\title{
Implementation of QbD Approach to the Analytical Method Development and Validation for the Estimation of Propafenone Hydrochloride in Tablet Dosage Form
}

\author{
Monika L. Jadhav and Santosh R. Tambe \\ Pharmaceutical Chemistry Department, M.G.V's Pharmacy College, Panchavati, Nashik 422003, India \\ Correspondence should be addressed to Monika L. Jadhav; monika.jadhav@yahoo.co.in
}

Received 9 January 2013; Accepted 26 February 2013

Academic Editor: Irene Panderi

Copyright (C) 2013 M. L. Jadhav and S. R. Tambe. This is an open access article distributed under the Creative Commons Attribution License, which permits unrestricted use, distribution, and reproduction in any medium, provided the original work is properly cited.

Chromatographic and spectrophotometric methods were developed according to Quality by Design (QbD) approach as per ICH Q8(R2) guidelines for estimation of propafenone hydrochloride in tablet dosage form. QbD approach was carried out by varying various parameters and these variable parameters were designed into Ishikawa diagram. The critical parameters were determined by using principal component analysis as well as by observation. Estimated critical parameters in HPTLC method include solvent methanol, mode of detection absorbance, precoated aluminium backed TLC plate $(10 \mathrm{~cm} \times 10 \mathrm{~cm})$, wavelength: $250 \mathrm{~nm}$, saturation time: $20 \mathrm{~min}$, band length: $8 \mathrm{~mm}$, solvent front: $70 \mathrm{~mm}$, volume of mobile phase: $5 \mathrm{~mL}$, type of chamber: $10 \mathrm{~cm} \times 10 \mathrm{~cm}$, scanning time: $10 \mathrm{~min}$, and mobile phase methanol : ethyl acetate : triethylamine $(1.5: 3.5: 0.4 \mathrm{v} / \mathrm{v} / \mathrm{v})$. Estimated critical parameters in zero order spectrophotometric method were solvent methanol, sample preparation tablet, wavelength: $247.4 \mathrm{~nm}$, slit width: 1.0 , scan speed medium, and sampling interval: 0.2, and for first order derivative spectrophotometric method it was scaling factor: 5 and delta lambda 4. The above methods were validated according to ICH Q2(R1) guidelines. Proposed methods can be used for routine analysis of propafenone hydrochloride in tablet dosage form as they were found to be robust and specific.

\section{Introduction}

Quality by Design approach suggests looking into the quality of analytical process during the development stage itself. It says that quality should be built into the process design rather than testing into final results of analytical process [1]. QbD is defined as "a systematic approach to development that begins with predefined objectives and emphasizes product and process understanding based on sound science and quality risk management" [2]. In alignment with the approach proposed in the draft FDA guidance for process validation, a three-stage approach [3] can be applied to method validation.

Stage 1. Method Design. Define method requirements and conditions and identify critical controls.

Stage 2. Method Qualification. Confirm that the method is capable of meeting its design intent.
Stage 3. Continued Method Verification. Gain ongoing assurance to ensure that the method remains in a state of control during routine use.

A critical function of Stage 1 is the design of an Analytical Target Profile (ATP) for the method. To design the ATP, it is necessary to determine the characteristics that will be indicators of method performance for its intended use. These are selected from the performance characteristics described in ICH Q2 as per the traditional approach [4]. Instead of being applied in a tick box manner, they are investigated by a risk assessment exercise as described in ICH Q9 [5] in combination with carefully designed development studies to identify the critical method and sources of variation [6]. Variables are then investigated by robustness and ruggedness experiments to understand the functional relationship between method input variables and each of the method performance characteristics and the results are compared to the desired outcome defined in the ATP. From this, one 


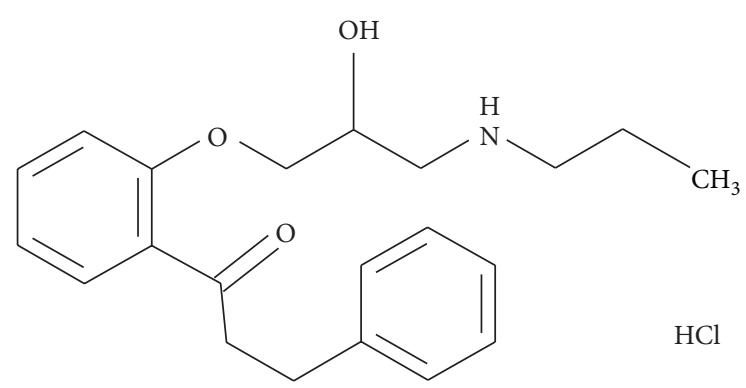

FIGURE 1: Chemical structure of propafenone hydrochloride.

can identify a set of operational method controls. Also, having evaluated the critical method parameters and gained a better understanding of the method through structured experimentation, a control strategy can be built into the method to ensure a consistent performance throughout its life cycle [7]. A key advantage of the QbD approach for all of the above situations is the flexibility to perform a qualification against the specific ATP defined for the intended use of the method [8].

Propafenone hydrochloride (PFH) (Figure 1) is Class 1C antiarrhythmic drug with local anesthetic effects and a direct stabilizing action on myocardial membranes [9]. Literature survey revealed that few chromatographic methods including enantiomeric separation using chiral stationary phases $[10$, 11] and liquid chromatography mass spectrometry [12] have been reported for determination of PFH from pharmaceutical formulation and biological fluids. Reported methods included use of chiral columns such as chiral AGP chiral pack $\mathrm{AD}$ [13] and involves various sophisticated techniques such as selected reaction monitoring mode via electrospray ionization [14]. Hence, it was planned to develop simple, economical, and less time consuming methods including High Performance Thin Layer Chromatographic method (method 1), zero order spectrophotometric method (method 2), and first order spectrophotometric method (method 3) for estimation of $\mathrm{PFH}$ using $\mathrm{QbD}$ approach. Applying the principles of $\mathrm{QbD}$ to analytical methods could result in more robust methods which produce consistent, reliable, and quality data throughout the life cycle and in turn will lead to less method incidents when used in the routine environment. This would mean less time spent on investigations and ultimately save time and money.

\section{Implementation of QbD Approach}

According to ICH Q8 (R2) guidelines, an experimental work was planned and $\mathrm{QbD}$ approach was implemented as follows.

2.1. Method Design. The method design stage includes establishing the method performance requirements, developing a method that will meet these requirements and then performing appropriate studies to understand the critical method variables that must be controlled to assure the method is robust and rugged.
2.2. Method Performance Requirements. Utilizing a QbD approach, it is essential at this stage that sufficient thought be given to the intended use of the method and that the objectives or performance requirements of the method be fully documented. This represents the Analytical Target Profile (ATP) [15] for the method.

ATP is the estimation of propafenone hydrochloride in tablet dosage form using spectrophotometric and chromatographic methods.

2.3. Method Development. Once the ATP has been defined, an appropriate technique and method conditions must be selected in order to meet the requirements of the ATP.

2.3.1. Method Understanding. Based on an assessment of risk (i.e., the method complexity and the potential for robustness and ruggedness issues) one can perform an exercise focused on understanding the method to better understand what impact key input variables might have on the method's performance characteristics. From this, one can identify a set of operational method controls.

2.3.2. Risk Assessment. Experiments can be run to understand the functional relationship between method input variables and each of the method performance characteristics. Knowledge accumulated during the development and initial use of the method provides input into a risk assessment (using tools such as the Fishbone diagram and FMEA) which may be used to determine which variables need studying and which require controls.

2.3.3. Design of Experiments. Robustness experiments are typically performed on parametric variables using Design of Experiments (DoE) to ensure that maximum understanding is gained while minimizing the total number of experiments. Depending on the type of method, surrogate measures of characteristics such as accuracy or precision may be evaluated.

2.4. Method Design Output. A set of method conditions will have been developed and defined which are expected to meet the ATP. Those conditions will have been optimized based on understanding of their impact on method performance.

QbD-based treatment of the robustness of an analytical method requires the assessment of all parameters (factors) which most strongly influence selectivity (results) alone and in combination. The experimental verification of many factors simultaneously is impractical and associated with extreme technical difficulties and expense. Some authors, have employed statistical studies, such as Plackett-Burman or fractional factorial designs and risk-based approaches [1620 ] to overcome the challenge and reduce the experimental workload. Other procedures include running automated robustness experiments [21-24]. The present paper, however, employs statistical analysis that is principal component analysis which exhibits factor extraction of variable parameters to evaluate robustness. 


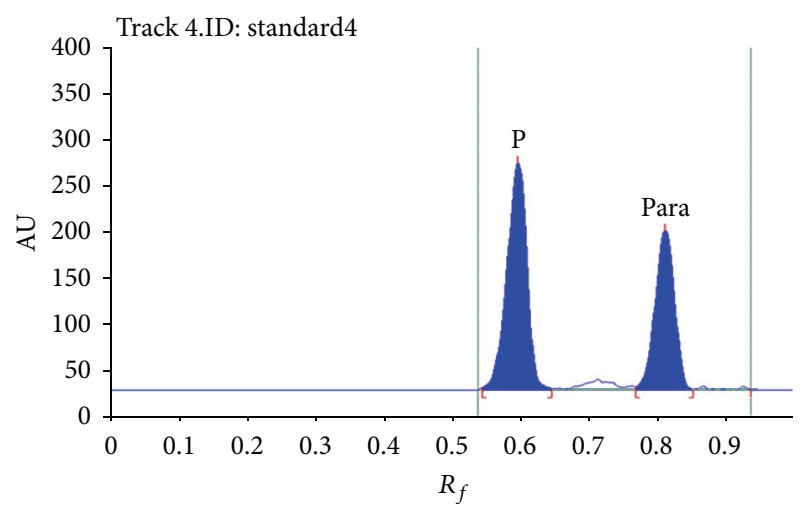

FIGURE 2: Densitogram of PFH and paracetamol (internal standard) for method 1 .

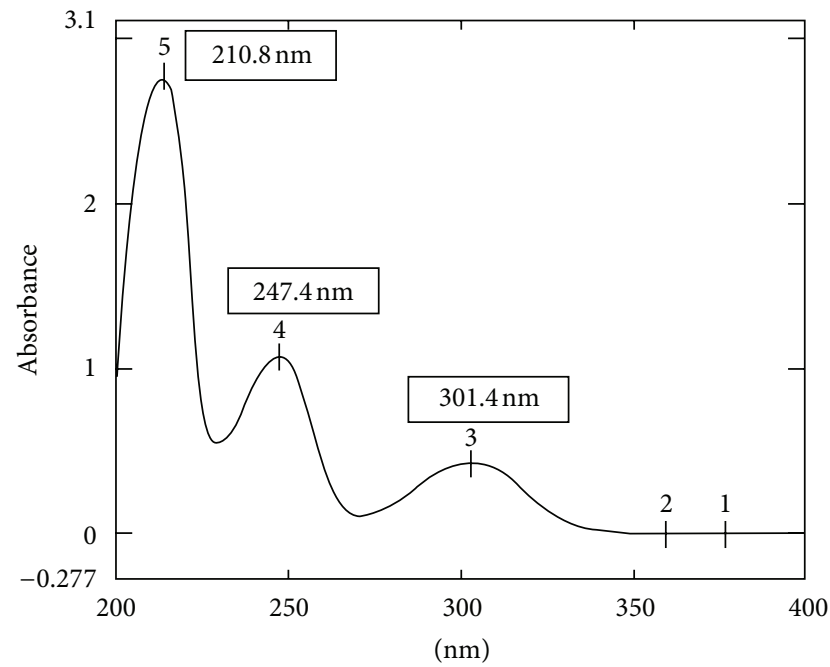

FIGURE 3: Spectrum of PFH in Methanol for method 2.

\section{Materials and Methods}

3.1. Chemicals and Reagents. PFH was procured from Procos and RLD Ltd., India. All chemicals and reagents used were of analytical grade and purchased from Merck chemicals, India. As the marketed formulation was not available, the internal formulation was prepared as tablet dosage form.

3.2. Instrumentation. Chromatographic measurements were carried out using Camag HPTLC, Wincats 1.4.2 software, Linomat 5 applicator, twin trough chamber, $100 \mu \mathrm{L}$ syringe, and TLC scanner 3. Spectrophotometric measurements were carried out using a double beam UV visible spectrophotometer of Shimadzu UV-2450 PC (Japan), UV Probe 2.21 software, and $10 \mathrm{~mm}$ path length with $1 \mathrm{~cm}$ quartz cells.

3.3. Chromatographic Conditions. Standard stock solution (400 ng-2400 ng) and internal standard paracetamol $(200 \mu \mathrm{g} / \mathrm{mL})$ were applied in the form of bandwidth $8 \mathrm{~mm}$ on precoated silica gel $60 \mathrm{~F}_{254}(10 \mathrm{~cm} \times 10 \mathrm{~cm} \times 0.2 \mathrm{~mm}$ thickness) plates using Camag Linomat 5 applicator. A

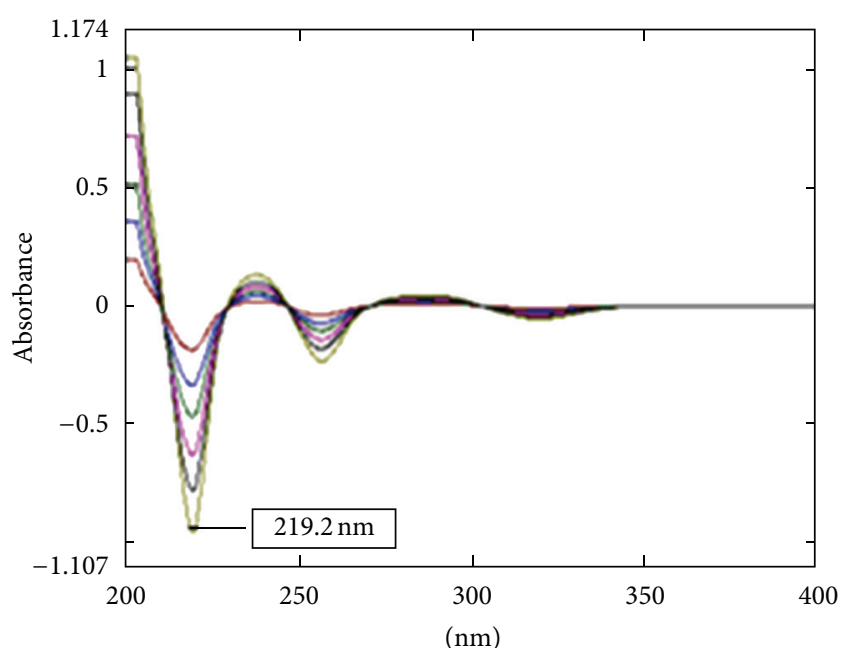

FIGURE 4: Linearity spectra of PFH in Methanol for method 3.

constant application rate $120 \mathrm{~nL} / \mathrm{sec}$ was employed and space between two bands was $14.0 \mathrm{~mm}$. The mobile phase methanol : ethyl acetate : triethylamine $(1.5: 3.5: 0.4 \mathrm{v} / \mathrm{v})$ was used. Linear ascending development was carried out in twin trough glass chamber of dimension $10 \mathrm{~cm} \times 10 \mathrm{~cm}$, saturated with mobile phase for $20 \mathrm{~min}$ at room temperature $\left(25 \pm 2^{\circ} \mathrm{C}\right)$. The length of chromatogram run was $70 \mathrm{~mm}$. Subsequent to the development, TLC plates were dried in current of air. Densitometric scanning was performed using Camag TLC scanner 3 in the absorbance mode at wavelength $250 \mathrm{~nm}$ (Figure 2).

3.4. Spectrophotometric Conditions. For the selection of analytical wavelength, standard solution of $\mathrm{PFH}$ was scanned in the spectrum mode from $400 \mathrm{~nm}$ to $200 \mathrm{~nm}$. From the spectrum, $\lambda$ max of PFH, $247.4 \mathrm{~nm}$ (Figure 3) was selected for method 2. Then it was transformed to its first derivative spectrum. It was found that $\mathrm{PFH}$ showed maximum amplitude at $219.2 \mathrm{~nm}$ (Figure 4) which was selected for method 3.

3.5. Preparation of Stock Standard and Working Solution. For both chromatographic and spectrophotometric methods, methanol was used as a solvent. Stock solution was prepared by dissolving $10 \mathrm{mg}$ of $\mathrm{PFH}$ in $10 \mathrm{~mL}$ volumetric flask and dissolved in methanol to obtain $1000 \mu \mathrm{g} / \mathrm{mL}$ concentration. Working solution $(50 \mu \mathrm{g} / \mathrm{mL})$ was used for initial spectral scan in spectrophotometric method and further dilutions for linearity were prepared from stock solution.

\subsection{Linearity Studies}

Method 1. From the stock standard solution $(1000 \mu \mathrm{g} / \mathrm{mL})$ $0.4,0.8,1.2,1.6,2.0$, and $2.4 \mu \mathrm{L}$ was applied on HPTLC plate to obtain the concentration of 400 to $2400 \mathrm{ng}$ per band and $0.2 \mu \mathrm{L}$ of internal standard (paracetamol $100 \mu \mathrm{g} / \mathrm{mL}$ ) was over spotted on each band. The plate was developed and scanned as per the optimized chromatographic conditions. $R_{f}$ values 
TABLE 1: Estimation of PFH in standard mixture.

\begin{tabular}{lccc}
\hline Method & Amount taken $(n=3)$ & Amount found $(\%)$ & $\%$ RSD \\
\hline 1 & $1500 \mathrm{ng}$ & 101.3 & 0.93 \\
2 & $15 \mu \mathrm{g} / \mathrm{mL}$ & 100.5 & 0.67 \\
3 & $15 \mu \mathrm{g} / \mathrm{mL}$ & 101.4 & 1.04 \\
\hline
\end{tabular}

and peak area were recorded for each concentration of drug. The calibration curve was plotted as drug concentration versus relative peak area. Regression equation, correlation coefficient, slope, and $y$-intercept are reported.

Method 2. Aliquot portions of about 0.1, 0.2, 0.3, 0.4, and $0.5 \mathrm{~mL}$ of standard stock solution $(1000 \mu \mathrm{g} / \mathrm{mL})$ were transferred to five different $10 \mathrm{~mL}$ volumetric flask and volume was made up to the mark with methanol (10$50 \mu \mathrm{g} / \mathrm{mL})$. Absorbances were recorded for each concentration at $247.4 \mathrm{~nm}$. Calibration graph was constructed by plotting absorbances versus concentrations in $\mu \mathrm{g} / \mathrm{mL}$. The regression equation and correlation coefficient are computed.

Method 3. A working standard of $100 \mu \mathrm{g} / \mathrm{mL}$ was prepared from standard stock solution. From this, aliquot portions of about $0.5,1.0,1.5,2.0,2.5$, and $3.0 \mathrm{~mL}$ were transferred to six different $10 \mathrm{~mL}$ volumetric flask and volume was made to the mark with methanol $(5-30 \mu \mathrm{g} / \mathrm{mL})$. These solutions were scanned in the spectrum mode from $400 \mathrm{~nm}$ to $200 \mathrm{~nm}$. Then it was transformed to its first derivative spectrum and amplitudes were noted at $219.2 \mathrm{~nm}$. Calibration graph was constructed by plotting amplitudes versus concentrations in $\mu \mathrm{g} / \mathrm{mL}$. The regression equation and correlation coefficient were calculated.

\subsection{Estimation of PFH in Standard Mixture and Tablet Dosage} Form. PFH was estimated by preparing standard mixture of label claim $150 \mathrm{mg}$ and it was diluted to make $15 \mu \mathrm{g} / \mathrm{mL}$ for methods 2 and 3 . For method 1, the concentration of $1500 \mathrm{ng}$ was applied on plate and then percentage amount was calculated (Table 1).

For the estimation in tablet dosage form, the internal formulation (tablet) containing $\mathrm{PFH}$ equivalent to $150 \mathrm{mg}$ was used. Twenty tablets were weighed and average weight was noted. Then the tablets were triturated and powder equivalent to average weight was weighed and transferred to $10 \mathrm{~mL}$ volumetric flask and diluted with $6 \mathrm{~mL}$ methanol. It was shaken for five minutes and this solution was filtered immediately through Whatman filter paper No. 41. Volume was adjusted up to the mark with methanol to obtain concentration $15000 \mu \mathrm{g} / \mathrm{mL}$. From this solution, dilutions were made according to respective method and percentage amount was calculated (Table 2).

3.8. Determination of Variable Parameters for Method 1. Variable parameters for method 1 were designed as Ishikawa diagram (Figure 5). For all the variable parameters plates were developed according to optimized method except changing particular variable parameter. Plates were scanned for each
TABLE 2: Estimation of PFH in tablet.

\begin{tabular}{lccc}
\hline Method & Amount taken $(n=3)$ & Amount found $(\%)$ & $\%$ RSD \\
\hline 1 & $1500 \mathrm{ng}$ & 98.83 & 0.84 \\
2 & $15 \mu \mathrm{g} / \mathrm{mL}$ & 99.05 & 1.24 \\
3 & $15 \mu \mathrm{g} / \mathrm{mL}$ & 99.49 & 0.97 \\
\hline
\end{tabular}

variable parameter and relative $R_{f}$ values and peak area were noted. Saturation time for the plate development was varied at various time intervals such as $0 \mathrm{~min}, 10 \mathrm{~min}$, $15 \mathrm{~min}, 20 \mathrm{~min}, 25 \mathrm{~min}, 30 \mathrm{~min}, 45 \mathrm{~min}$, and $60 \mathrm{~min}$. Band lengths were varied as $2 \mathrm{~mm}, 4 \mathrm{~mm}, 6 \mathrm{~mm}, 8 \mathrm{~mm}, 10 \mathrm{~mm}$, and $12 \mathrm{~mm}$. Also, development of chromatographic plate was performed by varying solvent front position of mobile phase. Various solvent fronts selected include $50 \mathrm{~mm}, 60 \mathrm{~mm}$, $70 \mathrm{~mm}, 80 \mathrm{~mm}$, and $90 \mathrm{~mm}$. Mobile phase volume was varied as $5 \mathrm{~mL}, 10 \mathrm{~mL}$, and $15 \mathrm{~mL}$. Development of plates was performed in three different types of twin trough chamber that are $10 \mathrm{~cm} \times 10 \mathrm{~cm}, 20 \mathrm{~cm} \times 10 \mathrm{~cm}$, and $20 \mathrm{~cm} \times 20 \mathrm{~cm}$. Duration of scanning after the development of plate was varied. Scanning time was altered in portions of time intervals that are $5 \mathrm{~min}, 10 \mathrm{~min}, 20 \mathrm{~min}, 30 \mathrm{~min}, 45 \mathrm{~min}, 60 \mathrm{~min}, 2$ hour, 5 hour, 1 day, 2 days, and 3 days. After the development of plate, scanning wavelength was also varied. The plate was scanned at $247 \mathrm{~nm}, 250 \mathrm{~nm}$, and $254 \mathrm{~nm}$. The composition of mobile phase was modified slightly and the variation in relative $R_{f}$ values and peak area was observed. Four mobile phase compositions were used as listed in the following.

Mobile phase 1: methanol : ethyl acetate : triethylamine $(1.5: 3.5: 0.1 \mathrm{v} / \mathrm{v})$.

Mobile phase 2 : methanol : ethyl acetate : triethylamine $(1.5: 3.5: 0.2 \mathrm{v} / \mathrm{v})$.

Mobile phase 3: methanol : ethyl acetate : triethylamine $(2: 3: 0.4 \mathrm{v} / \mathrm{v})$.

Mobile phase 4 : methanol : ethyl acetate : triethylamine $(2.5: 2.5: 0.4 \mathrm{v} / \mathrm{v})$.

Different detection mode at the stage of detection was selected. Detection was done in absorbance mode, reflectance mode, and fluorescent mode. Plate used for the development was not prewashed with methanol and plate development was carried out as such. Plate for the development was not activated in oven. Such plate was developed and results were recorded as relative $R_{f}$ values and peak area. Glass plate was used for development by maintaining all the standard conditions and results were observed.

3.9. Determination of Variable Parameters for Methods 2 and 3. According to $\mathrm{QbD}$ approach, the first step is to determine the variable parameters for the respective method. Thus, the variable parameters for both the spectrophotometric methods were designed as Ishikawa diagram (Figures 6 and 7).

For all the variable parameters as stated in Ishikawa diagram, the absorbances were recorded over the concentration range according to respective method. Working solution $(50 \mu \mathrm{g} / \mathrm{mL})$ was scanned from 400 to $200 \mathrm{~nm}$ and three 


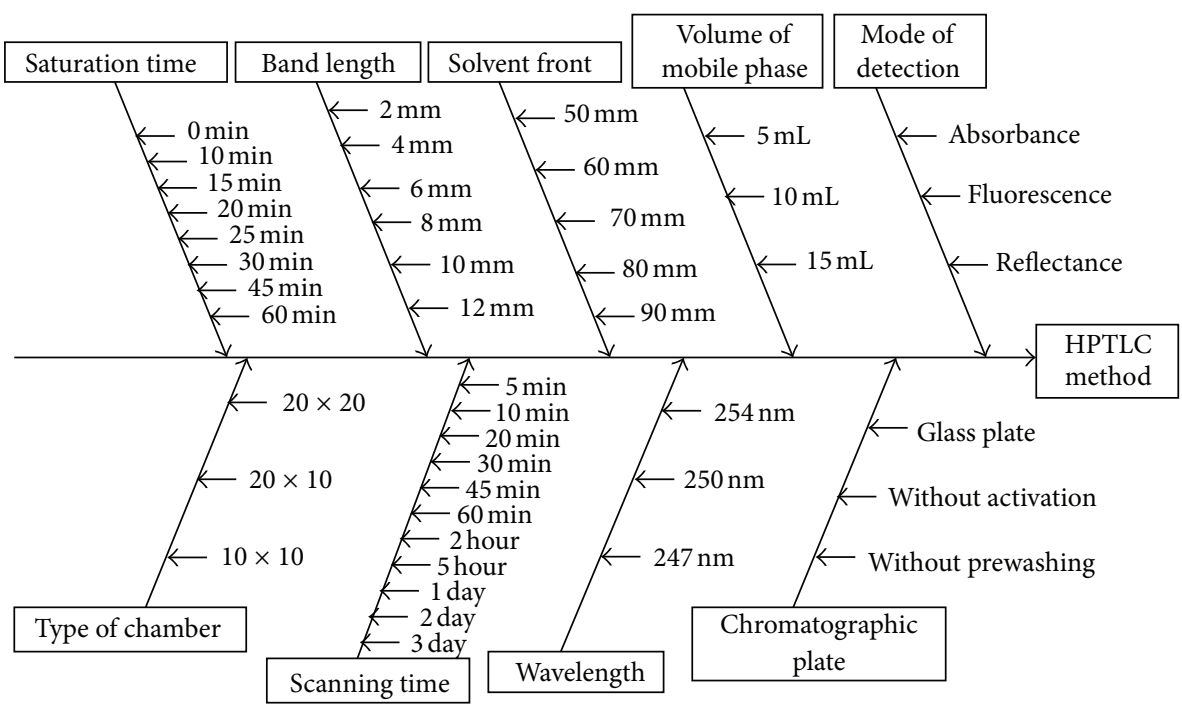

FIgURE 5: Ishikawa diagram for method 1.

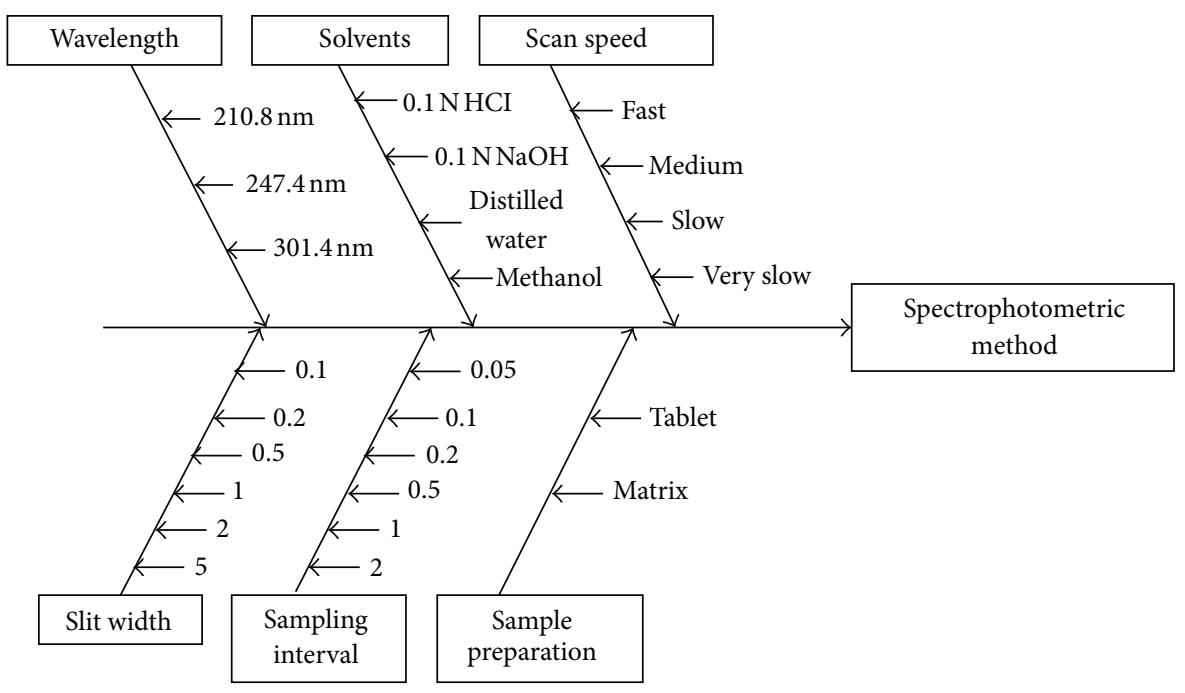

FIGURE 6: Ishikawa diagram for method 2.

peaks were observed at wavelengths $210.8 \mathrm{~nm}, 247.4 \mathrm{~nm}$, and $301.4 \mathrm{~nm}$. These three wavelengths were used as variable parameters. Also, the solubility was studied in various solvents including distilled water, $0.1 \mathrm{~N} \mathrm{NaOH}, 0.1 \mathrm{~N} \mathrm{HCl}$, and methanol. The sharpness of spectra was compared for selection of critical parameter. Scan speed was varied as fast, medium, slow, and very slow over the range 400$200 \mathrm{~nm}$, while slit width and sampling interval were varied in particular ranges of $0.1,0.2,0.5,1.0,2.0$, and $5.0 \mathrm{~nm}$ and $0.05,0.1,0.2,0.5,1.0$, and $2.0 \mathrm{~nm}$, respectively.

For the estimation of PFH, two types of sample preparations were selected and evaluated. Tablets were formulated as per the master formula and were used in method development. Average weight of tablets was noted and tablets were triturated. Tablet powder equivalent to average weight was taken for study. Matrix containing excipients like lactose monohydrate, microcrystalline cellulose, and corn starch was mixed with PFH and evaluated for the method development. Recovery study was carried out at three levels $80 \%, 100 \%$, and $120 \%$. For the optimization of first order derivative method, scaling factor and delta lambda were varied as 2, 3, 4, and 5 and 2, 4, 8, and 16, respectively. Amplitudes of linear concentrations were noted and evaluated.

3.10. Extraction of Critical Parameters. From the evaluated variable parameters, critical parameters were extracted by two ways, observation and principal component analysis using SPSS software. By comparing the spectral shape, sharpness, and absorbances of linearity and range, few parameters were selected as critical parameters. In principal component analysis, all these parameters were entered in variable entry window of SPSS software. Simultaneously, all the values of variable parameters were arranged in a datasheet. This datasheet was then substituted in the data entry window of 


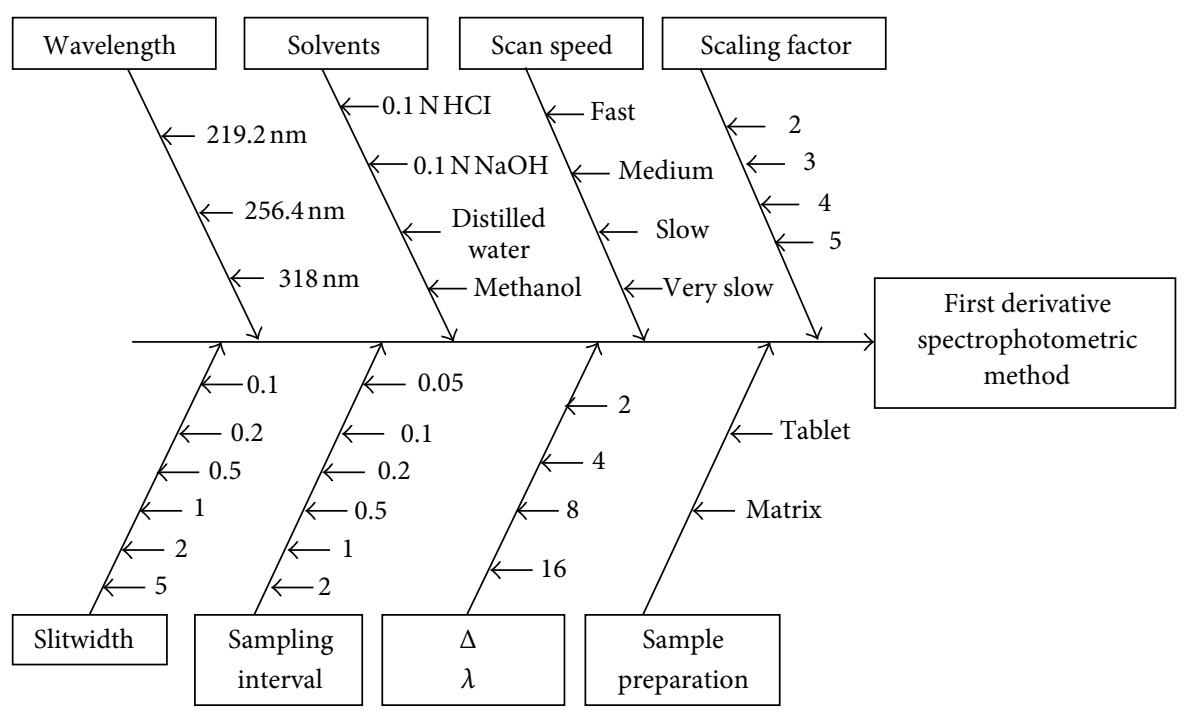

Figure 7: Ishikawa diagram for method 3.

SPSS software. Then the program was run to get principal components (critical parameters).

3.11. Validation. Validation was performed according to $\mathrm{ICH}$ Q2 (R1) guidelines. The parameters studied were linearity, precision, accuracy, specificity, LOD, LOQ, and robustness.

3.11.1. Precision. The reproducibility of all these three methods was determined by repeating the above methods at different time intervals (morning, afternoon, and evening) on the same day (Intraday precision) and on three consecutive days (interday precision). The intraday and interday variation for the estimation of $\mathrm{PFH}$ was carried out at three different concentration levels of 800,1200 , and $1600 \mathrm{ng} / \mathrm{band}$ for method 1 , then 20,30 , and $40 \mu \mathrm{g} / \mathrm{mL}$ for method 2 , and 10 , 15 , and $20 \mu \mathrm{g} / \mathrm{mL}$ for method 3 (Table 3 ).

3.11.2. Accuracy. The accuracy of the method was performed by calculating \% recovery of $\mathrm{PFH}$ by the standard addition method. Known amounts of standard solutions of $\mathrm{PFH}$ were added at $80 \%, 100 \%$ and $120 \%$ levels to prequantified sample solutions of PFH $(15 \mu \mathrm{g} / \mathrm{mL})$. At each level of the amount three determinations were performed. The amount of PFH was estimated by applying obtained values to regression equation. In method 1 , the known amount of standard stock solution of PFH was added to preanalyzed sample $(750 \mathrm{ng} / \mathrm{band})$. From the sample solution of tablet $(150 \mu \mathrm{g} / \mathrm{mL}), 5 \mu \mathrm{L}$ was applied and from the working standard solution $(100 \mu \mathrm{g} / \mathrm{mL}), 6 \mu \mathrm{L}, 7.5 \mu \mathrm{L}$, and $9 \mu \mathrm{L}$ was over spotted for $80 \%, 100 \%$ and $120 \%$ levels, respectively. The plate was developed and analyzed by the proposed method (Table 4).

3.11.3. Specificity. The interference of other excipients was evaluated by adding $20 \mu \mathrm{g} / \mathrm{mL}$ of microcrystalline cellulose (MCC), corn starch, and lactose monohydrate to the $15 \mu \mathrm{g} / \mathrm{mL}$ of sample solution separately and absorbance was
Table 3: Precision data.

\begin{tabular}{|c|c|c|c|}
\hline Method & Concentration & $\begin{array}{c}\text { Intraday (\% RSD) } \\
(n=3)\end{array}$ & $\begin{array}{c}\text { Interday (\% RSD) } \\
(n=3)\end{array}$ \\
\hline \multirow{4}{*}{1} & $800 \mathrm{ng}$ & 0.11 & 0.60 \\
\hline & $1200 \mathrm{ng}$ & 0.10 & 0.38 \\
\hline & $1600 \mathrm{ng}$ & 0.10 & 0.32 \\
\hline & Mean & 0.10 & 0.41 \\
\hline \multirow{4}{*}{2} & $20 \mu \mathrm{g} / \mathrm{mL}$ & 0.15 & 0.10 \\
\hline & $30 \mu \mathrm{g} / \mathrm{mL}$ & 0.10 & 0.07 \\
\hline & $40 \mu \mathrm{g} / \mathrm{mL}$ & 0.08 & 0.06 \\
\hline & Mean & 0.11 & 0.08 \\
\hline \multirow{4}{*}{3} & $10 \mu \mathrm{g} / \mathrm{mL}$ & 0.55 & 1.15 \\
\hline & $15 \mu \mathrm{g} / \mathrm{mL}$ & 0.59 & 1.19 \\
\hline & $20 \mu \mathrm{g} / \mathrm{mL}$ & 0.48 & 1.08 \\
\hline & Mean & 0.54 & 1.14 \\
\hline
\end{tabular}

TABle 4: Accuracy data.

\begin{tabular}{lccccc}
\hline \multirow{2}{*}{ Method } & \multirow{2}{*}{ Level } & \multicolumn{2}{c}{ Concentration } & \multirow{2}{*}{ \% Recovery } & Mean \\
& & Tablet & Standard & & \\
\hline \multirow{3}{*}{1} & $80 \%$ & 750 & 600 & 99.9 & \\
& $100 \%$ & 750 & 750 & 100.2 & 100.2 \\
& $120 \%$ & 750 & 900 & 100.6 & \\
\hline \multirow{3}{*}{2} & $80 \%$ & 15 & 12 & 100.1 & \\
& $100 \%$ & 15 & 15 & 99.9 & 100.1 \\
& $120 \%$ & 15 & 18 & 100.3 & \\
\hline & $80 \%$ & 15 & 12 & 99.9 & \\
& $100 \%$ & 15 & 15 & 100.8 & 100.4 \\
& $120 \%$ & 15 & 18 & 100.6 & \\
\hline
\end{tabular}

recorded. In method 1 , from the working standard solution $(1000 \mu \mathrm{g} / \mathrm{mL}), 1 \mu \mathrm{L}$ was applied (1000 ng) and $1 \mu \mathrm{L}(1000 \mathrm{ng})$ 
TABLE 5: Critical parameters extracted for method 1.

\begin{tabular}{|c|c|c|c|}
\hline \multicolumn{4}{|c|}{ Critical parameters extracted } \\
\hline \multicolumn{2}{|c|}{ By observation } & \multicolumn{2}{|c|}{ By principal component analysis } \\
\hline Parameter & Extracted result & Parameter & Extracted result \\
\hline \multirow{3}{*}{ Solvent } & \multirow{3}{*}{ Methanol } & Wavelength & $250 \mathrm{~nm}$ \\
\hline & & Saturation time & $20 \mathrm{~min}$ \\
\hline & & Band length & $8 \mathrm{~mm}$ \\
\hline \multirow{3}{*}{ Mode of detection } & \multirow{3}{*}{ Absorbance } & Solvent front & $70 \mathrm{~mm}$ \\
\hline & & Volume of mobile phase & $5 \mathrm{~mL}$ \\
\hline & & Type of chamber & $10 \mathrm{~cm} \times 10 \mathrm{~cm}$ \\
\hline \multirow{2}{*}{ Plate } & \multirow{2}{*}{ Precoated plate } & Scanning time & $10 \mathrm{~min}$ \\
\hline & & Mobile phase composition & $\begin{array}{l}\text { Methanol: ethyl acetate : triethylamine } \\
(1.5: 3.5: 0.4 \mathrm{v} / \mathrm{v})\end{array}$ \\
\hline
\end{tabular}

of each excipients was over spotted. The percentage of concentration was calculated.

3.11.4. Sensitivity. The limit of detection (LOD) and limit of quantification (LOQ) were calculated by using (1):

$$
\begin{aligned}
& \mathrm{LOD}=3.3 \times \frac{\sigma}{S}, \\
& \mathrm{LOQ}=10 \times \frac{\sigma}{S},
\end{aligned}
$$

where $\sigma$ is the standard deviation of intercept and $S$ is the slope of the calibration curve.

3.11.5. Robustness. Robustness of the method was assessed by making variations in solvent (ethanol) and wavelength $(248 \mathrm{~nm})$ for spectrophotometric methods. Linear concentration range was subjected to analysis and results were evaluated. In method 1, mobile phases having different compositions like methanol:ethyl acetate:triethylamine $(2: 3: 0.4 \mathrm{v} / \mathrm{v})$ and methanol: ethyl acetate: triethylamine $(2.5: 2.5: 0.4 \mathrm{v} / \mathrm{v})$ were tried and chromatograms were run. The duration of chamber saturation time was also varied as $20 \mathrm{~min}, 25 \mathrm{~min}$, and $30 \mathrm{~min}$.

\section{Results and Discussion}

Implementation of QbD approach was carried out by studying variable parameters in the analytical method development. Critical parameters were extracted by observation of results as well as performing principal component analysis. Also, each method was validated according to ICH Q2 (R1) guidelines.

4.1. Method 1. Method 1 has been developed and validated for the determination of PFH in pharmaceutical formulation. QbD approach was carried out by varying 46 parameters and critical parameters were extracted by using principal component analysis and by observation. The extracted critical parameters are summarized in Table 5.

PFH obeyed linearity in concentration range of 400$2400 \mathrm{ng} / \mathrm{band}$. The $R_{f}$ for $\mathrm{PFH}$ was found to be $0.60 \pm 0.02$
TABLE 6: Critical parameters extracted for method 2.

\begin{tabular}{lccc}
\hline \multicolumn{3}{c}{ Critical parameters extracted } \\
By observation & By principal component analysis \\
Parameter & Extracted result & Parameter & Extracted result \\
\hline \multirow{2}{*}{ Solvent } & \multirow{2}{*}{ Methanol } & Wavelength & $247.4 \mathrm{~nm}$ \\
Sample & & Scan speed & Medium \\
preparation & Tablet & Slit width & 1.0 \\
& & Sampling interval & 0.2 \\
\hline
\end{tabular}

TABLE 7: Critical parameters extracted for method 3.

\begin{tabular}{lccc}
\hline \multicolumn{4}{c}{ Critical parameters extracted } \\
By observation & By principal component analysis \\
Parameter & Extracted result & Parameter & Extracted result \\
\hline \multirow{3}{*}{ Solvent } & \multirow{2}{*}{ Methanol } & Wavelength & $219.2 \mathrm{~nm}$ \\
& & Scan speed & Medium \\
& & Scaling factor & 5 \\
Sample & \multirow{2}{*}{ Tablet } & Slit width & 1.0 \\
preparation & & Sampling interval & 0.2 \\
& & Delta lambda & 4 \\
\hline
\end{tabular}

and paracetamol was used as an internal standard with $R_{f}$ value $0.80 \pm 0.02$. The proposed method was applied for pharmaceutical formulation and percentage label claim for PFH was found to be $98.83 \%$. The amount of drug estimated by proposed method was in good agreement with the label claim. The method was validated for accuracy, precision, specificity, LOD, LOQ, and robustness. Accuracy of the method was checked by recovery study at three different levels, that is, $80 \%, 100 \%$, and $120 \%$. The $\%$ recovery of $\mathrm{PFH}$ was found to be $100.2 \%$. The method was found to be precise as indicated by the interday and intraday analysis showing \% RSD less than 2. There was no any interference of excipients showing that method was specific. Limit of detection and limit of quantitation were 35.4 and $107.4 \mathrm{ng} / \mathrm{band}$, respectively. The result did not show any statistical difference 
TABLE 8: Statistical data of Validation.

\begin{tabular}{lccc}
\hline Parameters & Method 1 & Method 2 & Method 3 \\
\hline$\lambda_{\text {max }}$ & 250 & $247.4 \mathrm{~nm}$ & $219.2 \mathrm{~nm}$ \\
Linearity range & $400-2400 \mathrm{ng}$ & $10-50 \mu \mathrm{g} / \mathrm{mL}$ & $5-30 \mu \mathrm{g} / \mathrm{mL}$ \\
Regression equation & $Y=0.339 X+0.131$ & $Y=0.019 X+0.0544$ & $0.029 X+0.035$ \\
Correlation coefficient $\left(R^{2}\right)$ & 0.99 & 100.07 & 0.99 \\
\% Recovery $(n=3)$ & 100.2 & $0.09 \mu \mathrm{g} / \mathrm{mL}$ & 100.4 \\
LOD & $35.4 \mathrm{ng}$ & $0.27 \mu \mathrm{g} / \mathrm{mL}$ & $0.48 \mu \mathrm{g} / \mathrm{mL}$ \\
LOQ & $107.4 \mathrm{ng}$ & 6537.84 & $1.44 \mu \mathrm{g} / \mathrm{mL}$ \\
Molar absorptivity $($ lit/mole/cm) & - & 0.058 & 13793.72 \\
Sandell's sensitivity $(\mu \mathrm{g} / \mathrm{sqcm} / 0.001)$ & - & & 0.027 \\
Precision (\% R.S.D.) & & 0.11 & 0.54 \\
$\quad$ Intra-day $(n=3)$ & 0.10 & 0.08 & 1.14 \\
$\quad$ Inter-day $(n=3)$ & 0.41 & $2.65 \times 10^{-4}$ & $2.38 \times 10^{-3}$ \\
Standard error & $0.168 \times 10^{-3}$ & 0.57 & 0.28 \\
Specificity (\% R.S.D.) & 0.55 & 0.84 & 0.57 \\
Robustness (\% R.S.D.) & 0.19 & & \\
\hline
\end{tabular}

between different solvents and different wavelengths suggesting that the method developed was robust. The statistical data of validation is summarized in Table 8 .

4.2. Method 2. A zero order spectrophotometric method has been developed and validated for the determination of $\mathrm{PFH}$ in pharmaceutical formulation. QbD approach was carried out by varying 19 parameters and critical parameters were extracted by using principal component analysis and by observation. The extracted critical parameters are summarized in Table 6.

PFH followed linearity in the concentration range of $10-$ $50 \mu \mathrm{g} / \mathrm{mL}$. The proposed method was applied for pharmaceutical formulation and percentage label claim was found to be $99.05 \%$. The amount of drug estimated by proposed method was in good agreement with the label claim. The $\%$ recovery for $\mathrm{PFH}$ was found to be $100.1 \%$. The method was found to be precise as indicated by the inter-day and intra-day analysis showing \% RSD less than 2. There was no any interference of excipients showing that the method was specific. Limit of detection and limit of quantitation were 0.09 and $0.27 \mu \mathrm{g} / \mathrm{mL}$, respectively. The result did not show any statistical difference between different solvents and different wavelengths suggesting that the method developed was robust. The statistical data of validation is summarized in Table 8.

4.3. Method 3. A first order derivative spectrophotometric method has been developed and validated for the determination of PFH in pharmaceutical formulation. QbD approach was carried out by varying 27 parameters and extracted critical parameters by using principal component analysis and by observation. The extracted critical parameters are summarized in Table 7.
PFH followed linearity in the concentration range of 5$30 \mu \mathrm{g} / \mathrm{mL}$. The proposed method was applied for pharmaceutical formulation and percentage label claim was found to be 99.49\%. The amount of drug estimated by proposed method was in good agreement with the label claim. The \% recovery for $\mathrm{PFH}$ was found to be $100.4 \%$. The method was found to be precise as indicated by the inter-day and intra-day analysis showing \% RSD less than 2. There was no any interference of excipients and no statistical difference between different conditions showing that the method was specific and robust. Limit of detection and limit of quantitation were 0.48 and $1.44 \mu \mathrm{g} / \mathrm{mL}$, respectively. The statistical data of validation is summarized in Table 8.

\section{Conclusion}

By comparing all three methods, it can be concluded that spectrophotometric method was found to be simple and rapid. First order spectrophotometric method was found to be more accurate as compared to zero order spectrophotometric method. Chromatographic method was found to be more accurate, precise, robust, and more sensitive as compared to both spectrophotometric methods. Statistical analyses prove that all the developed methods can be used for routine analysis of PFH in the tablet dosage form. Implementation of $\mathrm{QbD}$ approach resulted in more robust methods which can produce consistent, reliable, and quality data throughout the process and also save time and money.

\section{Acknowledgments}

The authors are thankful to the management, Principal Dr. R. S. Bhambar, and the staff of M.G.V's Pharmacy College, Panchavati, Nashik,for their kind help and support. 


\section{References}

[1] ICH Topic Q8 (R2), “ICH harmonised tripartite guideline," in Proceedings of the International Conference on Harmonisation of Technical Requirements for Registration of Pharmaceuticals for Human Use (ICH '09), Pharmaceutical Development, 2009.

[2] A. B. Godfrey and R. S. Kenett, "Joseph M. Juran, a perspective on past contributions and future impact," Quality and Reliability Engineering International, vol. 23, no. 6, pp. 653-663, 2007.

[3] P. Nethercote, P. Borman, T. Bennett et al., QbD for Better Method Validation \& Transfer, Pharmaceutical Manufacturing, 2010.

[4] ICH Topic Q2 (R1), "ICH harmonised tripartite guideline," in Proceedings of the International Conference on Harmonisation of Technical Requirements for Registration of Pharmaceuticals for Human Use (ICH '94), Validation of Analytical Procedures, 1994.

[5] ICH Topic Q9, "ICH harmonised tripartite guideline," in Proceedings of the International Conference on Harmonisation of Technical Requirements for Registration of Pharmaceuticals for Human Use (ICH '94), Quality Risk Management, 2005.

[6] P. Borman, P. Nethercote, M. Chatfield et al., The Application of Quality by Design to Analytical Methods, PharmTech, 2007.

[7] L. X. Yu, "Pharmaceutical quality by design: product and process development, understanding, and control," Pharmaceutical Research, vol. 25, no. 4, pp. 781-791, 2008.

[8] M. Pohl, M. Schweitzer, G. Hansen et al., "Implications and opportunities of applying the principles of $\mathrm{QbD}$ to analytical measurements," Pharmaceutical Technology Europe, vol. 22, no. 2, pp. 29-36, 2010.

[9] The United States Pharmacopoeia 27, the National Formulary 22, Asian Edition, United States Pharmacopoeial Convection, 2004.

[10] C. M. de Gaitani, V. L. Lanchote, and P. S. Bonato, "Enantioselective analysis of propafenone in plasma using a polysaccharide-based chiral stationary phase under reversedphase conditions," Journal of Chromatography B, vol. 708, no. 1-2, pp. 177-183, 1998.

[11] Y. Wu, M. Ma, and S. Zeng, "Enantioselective assay of S(+)- and $\mathrm{R}(-)$-propafenone in human urine by using RP-HPLC with precolumn chiral derivatization," Journals of Zhejiang UniversityScience A, vol. 5, no. 2, pp. 226-229, 2004.

[12] D. Zhong and X. Chen, "Enantioselective determination of propafenone and its metabolites in human plasma by liquid chromatography-mass spectrometry," Journal of Chromatography B, vol. 721, no. 1, pp. 67-75, 1999.

[13] L. R. P. de Abreu, V. L. Lanchote, C. Bertucci, E. J. Cesarino, and P. S. Bonato, "Simultaneous determination of propafenone and 5-hydroxypropafenone enantiomers in plasma by chromatography on an amylose derived chiral stationary phase," Journal of Pharmaceutical and Biomedical Analysis, vol. 20, no. 1-2, pp. 209-216, 1999.

[14] U. Hofmann, M. Pecia, G. Heinkele, K. Dilger, H. K. Kroemer, and M. Eichelbaum, "Determination of propafenone and its phase I and phase II metabolites in plasma and urine by highperformance liquid chromatography-electrospray ionization mass spectrometry," Journal of Chromatography B, vol. 748, no. 1, pp. 113-123, 2000.

[15] M. Schweitzer, M. Pohl, M. Hanna-Brown et al., "Implications and opportunities of applying QbD principles to analytical measurements," Pharmaceutical Technology, vol. 34, no. 2, pp. 52-59, 2010.
[16] R. M. Bianchini, P. M. Castellano, and T. S. Kaufman, "Development and validation of an HPLC method for the determination of process-related impurities in pridinol mesylate, employing experimental designs," Analytica Chimica Acta, vol. 654, no. 2, pp. 141-147, 2009.

[17] K. Monks, I. Molnar, H. J. Rieger, B. Bogati, and E. Szabo, "Quality by design: multidimensional exploration of the design space in high performance liquid chromatography method development for better robustness before validation," Journal of Chromatography A, vol. 1232, pp. 218-230, 2012.

[18] G. Srinubabu, C. A. I. Raju, N. Sarath, P. K. Kumar, and J. V. L. N. S. Rao, "Development and validation of a HPLC method for the determination of voriconazole in pharmaceutical formulation using an experimental design," Talanta, vol. 71, no. 3, pp. 1424$1429,2007$.

[19] S. M. Khamanga and R. B. Walker, "The use of experimental design in the development of an HPLC-ECD method for the analysis of captopril," Talanta, vol. 83, no. 3, pp. 1037-1049, 2011.

[20] E. M. Sheldon and J. B. Downar, "Development and validation of a single robust HPLC method for the characterization of a pharmaceutical starting material and impurities from three suppliers using three separate synthetic routes," Journal of Pharmaceutical and Biomedical Analysis, vol. 23, no. 2-3, pp. 561-572, 2000.

[21] P. F. Gavin and B. A. Olsen, "A quality by design approach to impurity method development for atomoxetine hydrochloride (LY139603)," Journal of Pharmaceutical and Biomedical Analysis, vol. 46, no. 3, pp. 431-441, 2008.

[22] B. Dejaegher and Y. vander Heyden, "Experimental designs and their recent advances in set-up, data interpretation, and analytical applications," Journal of Pharmaceutical and Biomedical Analysis, vol. 56, no. 2, pp. 141-158, 2011.

[23] D. Awotwe-Otooa, C. Agarabia, P. J. Faustinoa et al., "Application of quality by design elements for the development and optimization of an analytical method for protamine sulfate," Journal of Pharmaceutical and Biomedical Analysis, vol. 62, pp. 61-67, 2012.

[24] B. Vasselle, G. Gousset, and J. P. Bounine, "Development and validation of a high-performance liquid chromatographic stability-indicating method for the analysis of Synercid in quality control, stability and compatibility studies," Journal of Pharmaceutical and Biomedical Analysis, vol. 19, no. 5, pp. 641$657,1999$. 

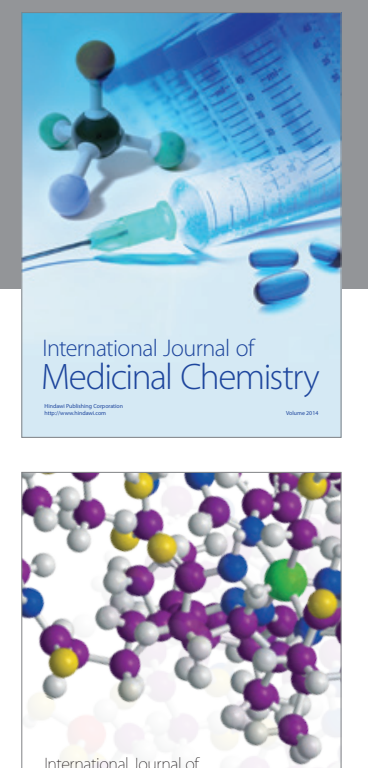

\section{Carbohydrate} Chemistry

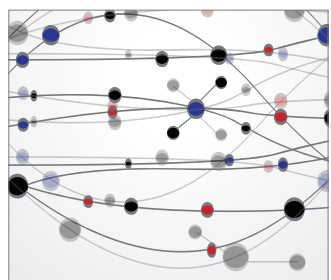

The Scientific World Journal
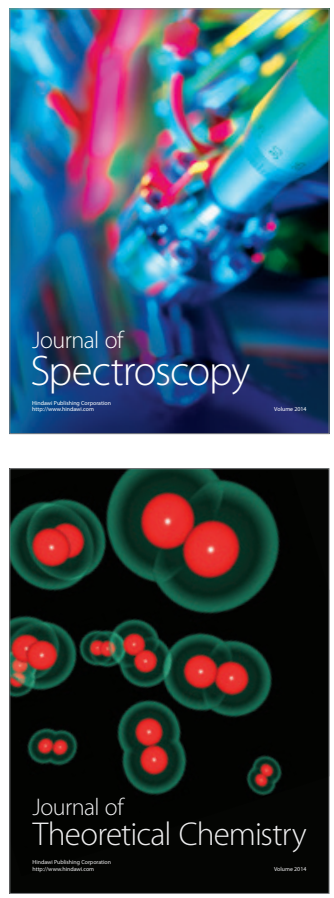
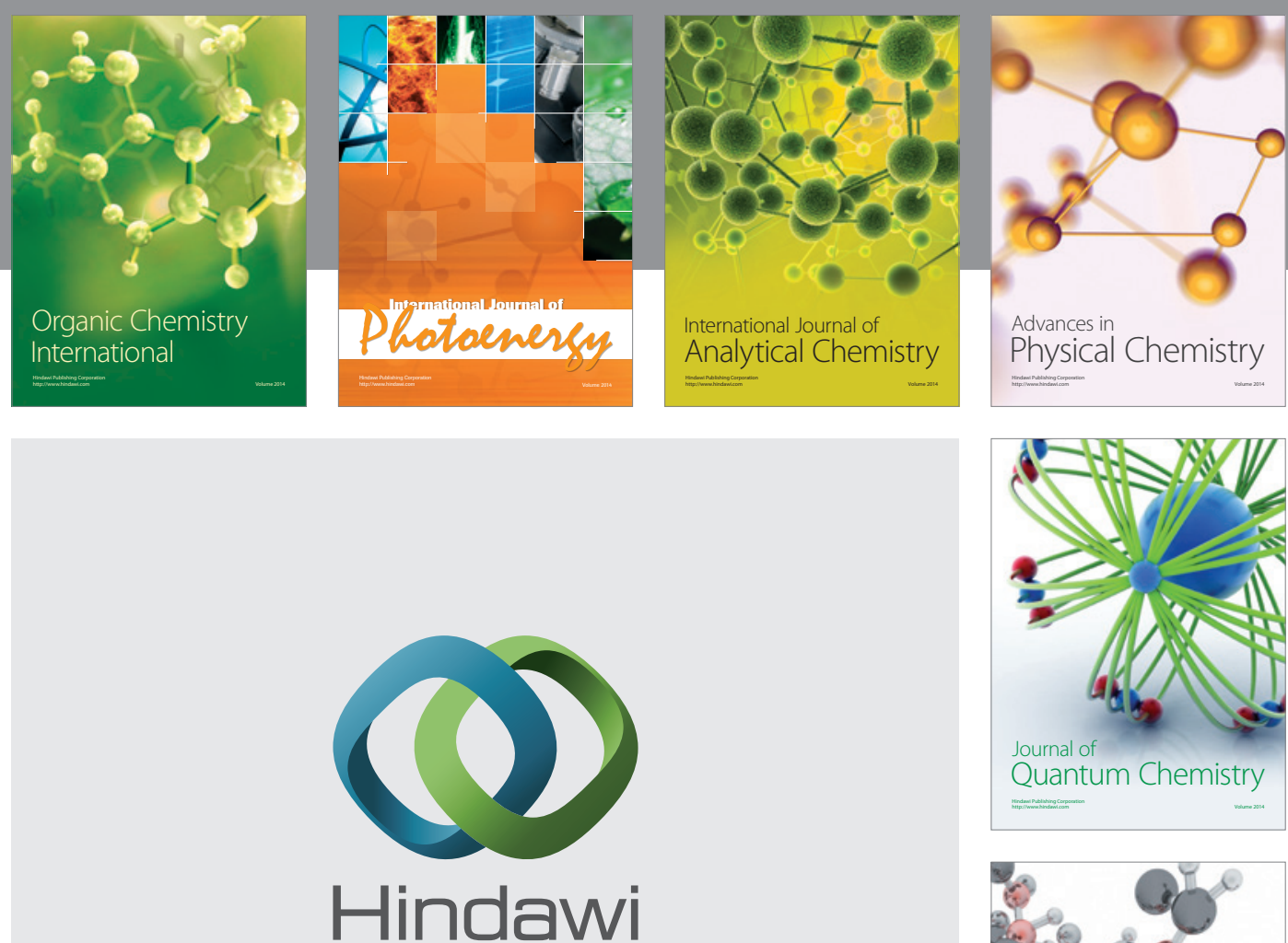

Submit your manuscripts at

http://www.hindawi.com

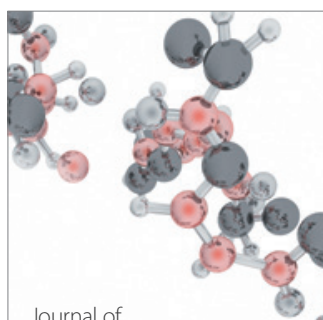

Analytical Methods

in Chemistry

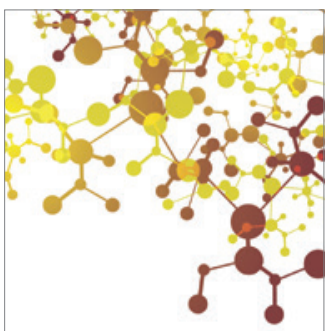

Journal of

Applied Chemistry

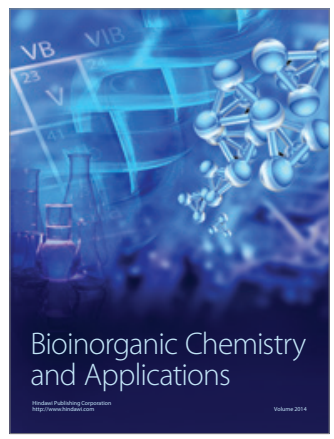

Inorganic Chemistry
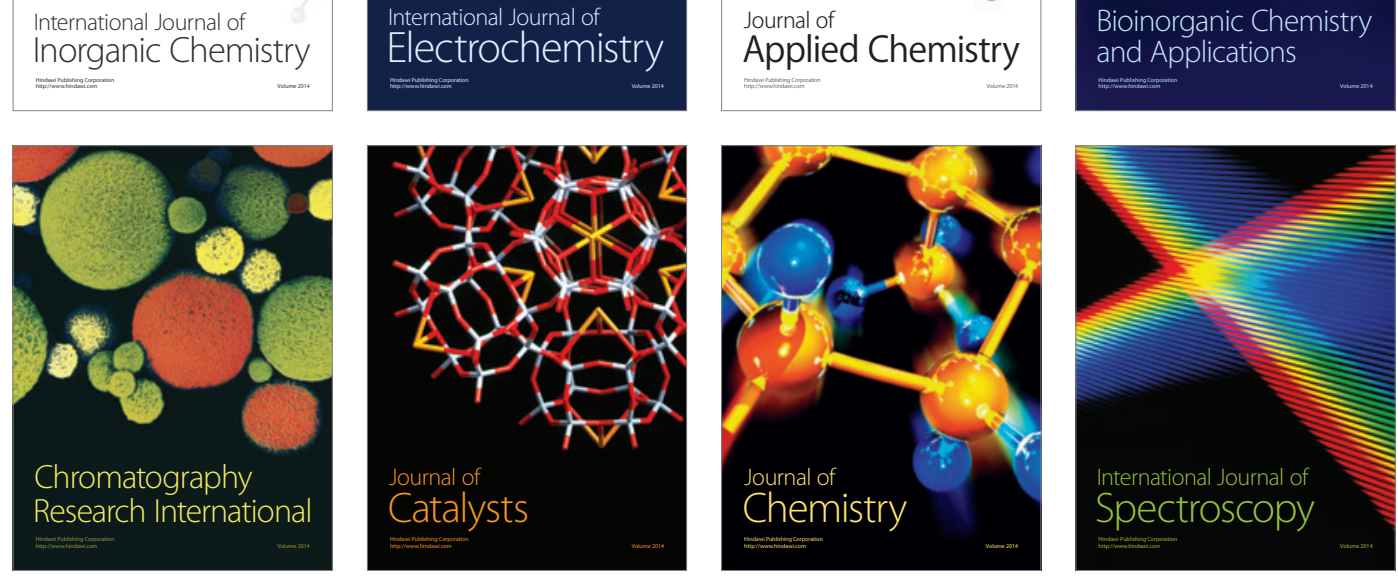